\title{
Visual, Auditory and Cross Modal Lexical Decision: A Comparison between Dyslexic and Typical Readers
}

\author{
Shelley Shaul \\ Edmond J. Safra Brain Research Center for the Study of Learning Disabilities, Department of Learning \\ Disabilites, Faculty of Education, University of Haifa, Haifa, Israel \\ Email: shelleys@edu.haifa.ac.il
}

Received 6 August 2014; revised 2 September 2014; accepted 28 September 2014

Copyright @ 2014 by author and Scientific Research Publishing Inc.

This work is licensed under the Creative Commons Attribution International License (CC BY). http://creativecommons.org/licenses/by/4.0/

(c) (i) Open Access

\begin{abstract}
This study examined the differences in processing between typical and dyslexic readers in a lexical decision task in different modalities (visual, auditory, and cross modality). In general, dyslexics exhibited slower reaction times and made more mistakes when performing the task. The biggest gap between the two groups of readers was found on the visual task. However, the dyslexics benefited from the cross modality presentation, with differences between the two groups minimized. The results of this study indicate that the slowness characteristic of dyslexics' stems mainly from slow processing of visual linguistic information and that supporting both processing systems relevant to reading will assist inter-sensory integration and may ease the word decoding process among dyslexics.
\end{abstract}

\section{Keywords}

Dyslexia, Lexical Decision, Visual, Auditory, Cross Modality

\section{Introduction}

Dyslexia, as suggested by the British Psychological Society, "is evident when accurate and fluent word reading and/or spelling develops very incompletely or with great difficulty” (p. 18). In other words, this definition assumes that reading failure among dyslexic readers stems not only from inaccurate word reading (see Compton \& Carlisle, 1994, for a review), but from dysfluent word decoding as an independent factor (see Wolf, 2000; Breznitz, 2006, for a review). Reading is an example of a cognitive activity that requires time-constrained information processing. Skilled reading of printed material requires rapid identification of written language representa- 
tions, as well as time-coordinated cross modal of visual, auditory, and semantic information (Breznitz, 2006; Seidenberg, 1990). The aim of this study is to investigate whether the slowness in one of these systems (visual, auditory, and cross modality) has a crucial effect on word decoding accuracy and fluency.

The Parallel Distributed Processing (PDP) model (Seidenberg \& McClelland, 1989) describes the word recognition process as reliant upon three processors: phonological, orthographic, and semantic. The reading process begins with visual recognition of the written grapheme code. Each written grapheme representation has a phonemic representation stored in the brain, which is processed when necessary by phonological mechanisms. The semantic processor relies on the mental lexicon.

According to the PDP model (Seidenberg, 1990), there is a flow of relevant information between different cerebral systems during word recognition. The amount of activity in each of these systems is different and based on the reader's needs and level of reading efficiency. Precise word recognition occurs when the phonological, orthographic, and semantic representations relevant to the decoding unit are evoked simultaneously (Breznitz, 2002a; Plaut et al., 1996). Precise word decoding demands that the information from these processors be integrated to produce the appropriate output (Breznitz, 2006).

Recent studies (Breznitz, 2001, 2006; Breznitz \& Misra, 2003) have identified an additional factor contributing to precise word decoding that is related to processing speed and synchronization between the visual-orthographic and auditory-phonological systems. As each sensory system has its own processing speed (see Breznitz, 2006 for review), a large speed of processing (SOP) gap between these systems may cause the "asynchrony" phenomenon, which disrupts the quality of integration of the relevant information necessary for decoding the word pattern, thereby causing word decoding failure (Breznitz, 2006).

For years, researchers have attempted to determine why $10 \%$ - $15 \%$ of the population is unable to acquire reading skills, despite the presence of sufficient intelligence, motivation, and learning opportunities and the absence of visual, auditory, mental, or primary motor impairment (Vellutino, Fletcher, Snowling, \& Scanlon, 2004). Most of the research on adult dyslexics indicates that children diagnosed as dyslexic in childhood remain so throughout their lives and can be classified into groups of compensated and non-compensated dyslexics (Lefly \& Pennington, 1991). It is customary to divide the population of adult dyslexics into two groups. The first group is the compensated dyslexics, whose reading is good enough to permit them to continue to learn in higher educational institutions. The second group is the non-compensated dyslexics, whose reading has stayed poor and therefore experience difficulties in their studies and many even do not finish high school (Pennington et al., 1986).

Research evidence has indicated that compensated dyslexics can, to some extent, overcome their word decoding difficulties but still remain slow readers. That is, word decoding remains a slow process which impairs the reading comprehension among this population (Ben Dror, Pollatsek, \& Scarpati, 1991; Bruck, 1992, 1998; Brunswick et al., 1999; Gallagher, Laxon, Armstrong, \& Frith, 1996; Lefly \& Pennington, 1991; Shaywitz et al., 1999). However, the source of their continued reading failure has not yet been fully identified.

Many researchers have suggested that the main source of dyslexics' word decoding deficit lies in difficulties with the phonological system (Bruck, 1992, 1998; Elbro, Nielsen, \& Peterson, 1994; Flowers, 1995; Gottardo, Siegel, \& Stanovich, 1997; Leong, 1999; Shaywitz, 1996; Shaywitz et al., 1999; Snowling \& Nation, 1997; Snowling, Nation, Maxham, Gallagher, \& Frith, 1997). Phonological processing is the ability to use information on the sound structure of language for processing written and spoken language. Evidence has shown that phonological processes, especially phonological awareness and segmentation ability, are crucial for the development of precise reading, and that without phonological decoding (converting the visual letter into its sound), readers are unable to learn the alphabetic principle (Rayner et al., 2001; Share, 1994; Treiman, 2000).

Additional studies have indicated that another source of reading difficulty among dyslexics is related to orthographic processing failure. Orthographic knowledge is related to the visual information of a word, specifically the letters that comprise lexical patterns and their order in a word, which contributes to spelling ability as well as the ability to identify the visual pattern of a word (Corcos \& Willows, 1993; Wagner \& Barker, 1994). Indeed, one of the main characteristics of adult dyslexia is a spelling deficit. It has been claimed that spelling errors and letter order confusion stem from processing difficulties and a lack of orthographic knowledge (Brunswick et al., 1999; Elbro, Nielson, \& Peterson, 1994; Shaywitz et al., 1999).

Recent studies have indicated another important dimension associated with word decoding, namely, reading fluency. The fluency factor is an additional component of the accuracy of word decoding processes and is an inseparable aspect contributing to the quality of word decoding. Word decoding fluency is expressed by rapid decoding (Torgesen et al., 2000) and as such serves as a measure of decoding quality. Decoding speed is measured 
by the number of words that a person reads correctly within a limited time (Breznitz, 2001; Compton \& Carlisle, 1994; Greene \& Royer, 1994). The claim that decoding speed leads to reading fluency stems, among others, from a general ability related to speed of information processing (Kail \& Hall, 1994) and to the systems relevant to the decoding process in reading (Breznitz, 2002a).

The entire cognitive processing time relies on the SOP of each of the factors and processes active during the performance of a particular task (Kail, 1991). It has been suggested that a number of factors contribute to SOP, including stimulus complexity and modalities, the differential SOP of each processing stage in the information processing system (Kail, 1991), and the basic SOP of the information processor (Hale, 1990).

Numerous studies have indicated that some dyslexics' exhibit a visual processing difficulty and in particular a variance in non-linguistic visual processing between typical and dyslexic readers. Dyslexics have been found to experience problems performing visual tasks that require rapid temporal processing of information (Lovegrove et al., 1996). Research findings point to a scarcity of magno-type visual cells among dyslexics as the cause of their slow processing of visual information (Lovegrove \& Slaghuis, 1989; Stein \& Walsh, 1997; Willows, Kruk, \& Corcos, 1993). Anatomy studies have shown that in the thalamic nucleus (LGN), where the visual information arrives, the cells of dyslexics are 30\% smaller than those of typical readers (Galaburda \& Livingstone, 1993). In addition, evidence has been found for structural deficits (anatomical differences) in the transitive visual system among dyslexics (Livingstone et al., 1991).

A number of research studies have indicated deficits among dyslexics in the visual-orthographic processing system as well. These deficits are also expressed in accuracy and slow reaction time on tasks examining orthographic skills. For example, evidence was found indicating a positive connection between word recognition difficulties and problems with orthographic processes (Bowers et al., 1994; Reitsma, 1989). Zecker (1991) found that dyslexics were slower than typical readers when using orthographic information. When they were required to decide whether two words were orthographically similar or different, rhymed or not, typical readers responded more quickly when there was orthographic similarity while there was no difference in response time among dyslexics.

According to Wolf, Vellutino, and Gleason (1998), the general visual form of a given word is perceived within 60 - 80 msec from onset. In a study that examined word recognition, the stimuli were presented to the subjects for $60 \mathrm{msec}$ in order for them to process the orthographic information. Adult dyslexics managed to recognize 14 out of 52 words at an average reaction time of $1161 \mathrm{msec}$, whereas the control group recognized 34.4 words with an average reaction time of $690 \mathrm{msec}$ (Leinonen, Leppanen, Aro, Ahonen, \& Lyytinen, 2001).

Many studies have examined auditory processing among dyslexics as compared to typical readers (Stein \& McAnally, 1995). Findings show brain damage in Perisylvian locations in the temporal and frontal cortex, mainly in the left hemisphere. This tissue is involved in both the primary auditory cortex and the area related to associative activity (Galaburda, 1993; Galaburda, Sherman, Rosen, Aboitiz, \& Geschwind, 1985). The most extensive damage was found in the anterior areas (Hynd \& Semrud-Cli, 1989).

It seems that these neuroanatomical studies support the view that a number of forms of dyslexia have a complex neurological basis, involving various senses and associative areas of the brain. In an MRI study, Leonard et al. (1993) found abnormal anatomical patterns, among others, a change in the left plenum temporal (in the parietal lobe), as well as a structural change including longer sylvian fissures in the left hemisphere and additional supermarginal gyrus relative to the norm.

It has been claimed that young dyslexic readers have specific difficulty with rapid temporal processing of auditory information (Eden, Stein, Wood, \& Wood, 1990; Shapiro, Ogden, \& Lind-Bald, 1993; Tallal, Miller, \& Fitch, 1995). Some researchers go even further, claiming that the temporal processing deficit among dyslexics exists in all modalities, not only auditory. For instance, Farmer and Klein (1995) and Merzenich, Schreiner, Jenkins, and Wang (1993) have suggested that dyslexics suffer from a general sensory difficulty in temporal processing.

In light of the plethora of evidence indicating that the phonological channel is impaired among dyslexic readers, it is possible that the failure to read phonemic units is based, among other things, not only on inaccuracy but on slow processing in the phonological channel. Efficient cognitive processing containing information from several cerebral systems necessitates informative serial temporal coordination (Kolers \& Brewster, 1985). This type of processing constitutes a component of linguistic processing (Robinson, 1977), memory (Neisser, 1967), and perception (Friedes, 1974).

The entire reading process requires information processing, starting with a stimulus that enters the system, 
passes the perception and encoding stage, enters short-term memory under the correct circumstances and from there to long-term memory. In order for the reading process to be performed efficiently, cross modal integration between the different stages is required, with precise timing of stimuli arriving from the visual and auditory systems. A stimulus that is not speedily and efficiently perceived and encoded in short-term memory is removed from the system as if never perceived. Cognitive activity of all kinds requires precise scanning processes as stimuli enter the system one after the other (auditory stimuli) or as a complete unit (visual stimuli). Slow processing of one stimulus may inhibit or prevent processing of the next (Stigler, Nusbaum, \& Chalip, 1988).

Reading is a task requiring translation of the visual code into an auditory one (Freides, 1974). In the 1960s and 1970s, a theory emerged explaining reading impairment in terms of an inter-sensory cross modal failure, and this assumption was investigated in numerous studies examining the extent to which information transferred from one sensory modality becomes available to another (Birch \& Belmont, 1964, 1965; Blank \& Bridger, 1966; Muehl \& Kremenak, 1966). Birch and Belmont (1964) developed a theory according to which deficient readers have difficulty with integrating information arriving from different sensory modalities. They tested this theory by comparing typical and impaired readers' ability to judge the correlation between simple rhythm patterns (auditory) and dot patterns (visual). Many researchers attempted to replicate their experiments and obtained similar results (Beery, 1967; Muehl \& Kremenak, 1966; Sterritt \& Rudnick, 1966).

In the past few years, research into the cross modal theory has returned to the fore following construction of the PDP theory as well as the emergence of evidence related to intra-sensory temporal processing as a central factor in the reading process. The focus of this research deals with the cross modal between the auditory-phonological and visual orthographic modalities as well as with the cross modal within each of these as a measure of the quality of the reading process. For instance, Bowers and Wolf (1993) hypothesized that deficits in processing speed, as measured by rapid automatic naming (RAN) naming tests, may be a "marker" for disturbances in the timing ability and automaticity when processing orthographic codes and their phonological representations. According to these researchers, impaired orthographic patterns develop when phonological units are not available in time for cross modal with letter sequences. Moreover, they also maintain that skilled readers must visually process each letter in a word and match them to their phonological representation, with slow encoding of single letters and/or complex patterns of words affecting the reading rate of words and pseudowords.

Yap and Van der Leij (1993a) also confirmed the claim that dyslexic readers have difficulty in coordinating between visual and auditory stimuli presented to them. They also found that the ability to coordinate stimuli among these readers was impaired during the visual and auditory presentation of simple stimuli, which requires automatic processing (digits). The researchers claimed that dyslexic children have a problem with temporal discrimination within and between sensory modalities, with their main difficulty being parallel processing of stimuli.

An additional study conducted by Rose, Feldman, Janowski, and Futterweit (1999) examined the cross modal ability of dyslexics using pair judgments of non-linguistic stimuli, with both stimuli being either from the same modality or from one visual and one auditory modality. It was found that these measures significantly explained the differences in reading ability between subject groups and that the dyslexics were less accurate and slower on all task types.

Recent research studies using imaging and cerebral activity examination techniques found that the left area of the angular gyrus, which is responsible for combining orthographic, phonological, and semantic information, is connected to dyslexia. One hypothesis is that the connections between this area and other regions in the cortex among dyslexic readers are less efficient than among typical readers (Poldrack, 2001). It has been claimed that dyslexics have greater difficulty in transferring or receiving information accurately to and from the left angular gyrus and other areas in the brain.

Furthermore, it has also been claimed that the reading process, which involves different sensory systems, is a cerebral activity dispersed across different brain regions (Demb, Poldrack, \& Gabrieli, 1999), thus highlighting the importance of the cross modal process for communication and transfer of information between the different areas involved in the reading process. Further evidence pointing to problems of the angular gyrus area among dyslexics was found in studies that compared blood flow between typical and dyslexic readers. The studies identified a reduced blood flow in this area among dyslexics (Rumsey et al., 1994) and found that the connections between primary sensory areas and integrative regions are different between these two groups (Hayes, Warrier, Nicol, Zecker, \& Kraus, 2003). In addition, postmortem structural evidence has demonstrated differences between dyslexics and typical readers in this area of the brain (Humphreys, Kaufmann, \& Galaburda, 1990). 
In sum, consistent evidence has validated the claim that dyslexics have a problem with basic lower level processing in the visual, auditory and cross modal stimuli (Harrar, Tammam, Perez-Bellido, Pitt, Stein, \& Spence, 2014). It has been claimed that this failure stems, among others, from impaired brain structures which are necessary for activity related to visual, auditory and inter-sensory cross modal (Bolmert, 2011). The questions which arise from theses finding are do these difficulties play a role in higher level linguistic processing of these modalities while processing words and pseudo words, an additional question is whether the intersensory cross modal deficit in these level also stems from a larger SOP gap between the visual-orthographic and auditory phonological systems. This gap may provide deficient information to the cerebral areas responsible for inter-sensory cross modal and thus disrupt word decoding accuracy in reading.

Word decoding relies on the processing within and between different modalities (visual and auditory) and, among others, on the precise cross modal of this information. Therefore this study examines the SOP and the accuracy of processing in the relevant modalities of reading, including visual, auditory and cross modal, by using stimuli presented to each channel separately and to both channels simultaneously, all among the same subjects as compared to previous studies which usually examine only one channel. It is assumed that differences will be found between dyslexic and typical readers in terms of SOP during the processing of a lexical decision task in all the modalities, in addition it is expected to find a different prolife of processing in the three different modalities among adult dyslexic readers as compared to typical readers which we assume will do well in all modalities.

\section{Method}

\subsection{Subjects}

The experimental group consisted of 20 dyslexic university students, aged 20 - 27 who had been diagnosed as dyslexic in childhood and as adults approached the university to accommodate them on the basis of their reading deficit. All students scored at least one standard deviation below average on word decoding measures (criterion for the definition of dyslexia, NICH, 2001; Ministry of Education Report, Breznitz, 2002b). The control group consisted of 20 typical reading university students, chronologically age-matched to the experimental group. All subjects exhibited average reading ability and above. The experimental and control groups were matched not only for age, but also for gender, IQ, and socio-economic status. They were all right-hand dominant, native speakers of Hebrew, with normal hearing and vision, and without known neurological problems or history of developmental attention disorder. None of the subjects were taking prescribed medications and all were paid volunteers

\subsection{Measures}

\subsubsection{Group Validation Measures}

1) Background measures:

A battery of tests was administered in order to validate the subjects' allocation to the experimental or control groups, as follows:

a) General Ability: Raven Standard Progressive Matrices (Raven, 1965).

b) Attention: D2 test (Brickenkamp \& Zillmer, 1995).

2) Reading Measures:

Reading measures included decoding and comprehension. The measures were scored for accuracy and performance time.

3) Decoding accuracy:

a) One-minute tests of reading words and pseudowords (Shatil, 1997).

b) Reading text in context (The National Center for Evaluation, 2000).

c) Comprehension: Comprehension during silent and oral reading (The National Center for Evaluation, 2000). The subjects read two texts, one silently and one orally. They were then required to answer multiple choice questions for each passage. Total comprehension score for each sub-test ranged from 0 - 5.

\subsubsection{Experimental Measures}

This study used behavioral measures of accuracy and reaction time for each experiment. 
In order to examine the various synchronization processes during word decoding, a lexical decision task was used in which the subject was required to decide whether a sequence of letters presented (visual/auditory) constituted a real word in spoken language or a pseudoword. Distinguishing words from pseudowords reflects word decoding ability as a measure of reading quality (Perfetti, 1994).

Based on the lexical decision paradigm, the research tasks were comprised of sub-tasks according to the sensory modalities in which the stimuli were presented. Each subtest consisted of 120 stimuli, half of which were words and half pseudowords. All of the stimuli were comprised of 2 - 3 syllables ( 4 - 6 letters) representing the sounds in the language. The words were names of objects with medium frequency in the Hebrew language (taken from Frost, 2001). The pseudowords were based on the real words by replacing a letter or syllable and creating a new meaningless stimulus.

The stimuli were presented visually, aurally, and simultaneously. The visual stimuli presented on the computer screen were $3 \mathrm{~cm}$ in height and $4-5 \mathrm{~cm}$ in length. The subjects were seated at a distance of $1 / 2$ meter in front of the computer. The auditory stimuli were recorded in stereo $44 \mathrm{kHz}, 16$ bits by a professional announcer in a recording studio and were presented to the subjects via headphones. All the stimuli, words and pseudowords, were presented randomly, and the ISI between stimuli was $2000 \mathrm{msec}$ (approximate time for stimulus decay). Subjects were instructed to press a joystick button when the stimulus was a word and another button when it was a pseudoword, and the reaction time and accuracy of each subject was measured in response to these tasks.

1) Visual lexical decision

Examination of the rate and accuracy of processing within the visual channel was carried out by the presentation of each stimulus for $200 \mathrm{msec}$ to the center of the computer screen. Time was selected by a pilot test.

2) Auditory lexical decision

Examination of the rate and accuracy of processing within the auditory channel was carried out by the auditory presentation of each stimulus via headphones for $500 \mathrm{msec}$ word (play range was between 450 - $550 \mathrm{msec}$ ).

3) Cross modal task

Each word was presented to the subject via headphones for 500 - 550 msec and was displayed on a computer screen simultaneously for the same time duration.

\subsection{Procedure}

The testing procedure was administered to each participant over two sessions in the Laboratory for Neurocognitive Research at the University of Haifa. The study was carried out in a sound attenuated room. Each session lasted approximately 1.5 to 2 hours. In the first session, reading level was tested and only those subjects deemed suitable were included in the sample. The behavioral tests were then administered. In the second session, the subjects performed the different experimental tasks.

\section{Results}

\subsection{Validation of Experimental Groups}

General Ability Tests: The general ability tests were administered in order to validate that the subjects possessed an average IQ or above and that there was no difference between the groups in terms of IQ.

Reading Tests: Significant differences were found for all reading measures. The dyslexics read words and pseudowords out of context slower and with more errors than the typical readers. Moreover, their silent and oral text reading was slower and with more errors as compared to the typical readers. No significant reading comprehension differences were found between the dyslexics and the typical readers. These results can be seen in Table 1 which shows the means, standard deviations, and t-test scores for the reading measures.

\subsection{Results of the Behavioral Measures (Reaction Time and Task Accuracy)}

The means, standard deviations, and t-test results for the various lexical decision tasks are presented in Table 2 it can be seen that there were differences between the two groups only in the visual and cross modal tasks.

\subsubsection{Visual Lexical Decision}

When the stimulus was presented to the visual field, the reaction time of the dyslexics was longer than that of the typical readers. In addition, the pseudo word recognition accuracy of the dyslexics was lower than that of the 
Table 1. Means and standard deviations for reading measures.

\begin{tabular}{|c|c|c|c|c|c|}
\hline \multirow{2}{*}{ Measure } & \multicolumn{2}{|c|}{ Typical readers $(\mathrm{N}=20)$} & \multicolumn{2}{|c|}{ Dyslexic readers $(\mathrm{N}=20)$} & \multirow{2}{*}{$\mathrm{T}$} \\
\hline & Mean & S.D. & Mean & S.D. & \\
\hline \multicolumn{6}{|l|}{ Words per minute } \\
\hline Correct words & 110.8 & 12.61 & 73.00 & 23.19 & $-6.40^{* * *}$ \\
\hline No. errors & 0.85 & 1.26 & 2.05 & 1.76 & $2.44^{* *}$ \\
\hline \multicolumn{6}{|l|}{ Pseudowords per minute } \\
\hline Correct pseudowords & 70.95 & 20.56 & 35.20 & 13.27 & $-6.15^{* * *}$ \\
\hline No. errors & 3.45 & 4.78 & 10.55 & 9.05 & $3.10^{* *}$ \\
\hline \multicolumn{6}{|l|}{ Oral text reading } \\
\hline Reading time (sec) & 92.01 & 12.36 & 129.21 & 33.2 & $4.69^{* * *}$ \\
\hline Reading errors & 0.75 & 0.96 & 5.55 & 3.57 & $5.79^{* * *}$ \\
\hline Correct of 5 & 4.15 & 1.30 & 3.95 & 0.94 & -0.55 \\
\hline \multicolumn{6}{|l|}{ Silent text reading } \\
\hline Reading time (sec) & 84.04 & 40.70 & 119.93 & 51.46 & $2.45^{*}$ \\
\hline Correct of 5 & 3.00 & 1.16 & 3.00 & 1.25 & 0.00 \\
\hline
\end{tabular}

${ }^{*} p<0.05 ;{ }^{* *} p<0.01 ;{ }^{* * *} p<0.001$.

Table 2. Means, standard deviations, and t-test for the lexical, auditory, and cross modal lexical decision tasks.

\begin{tabular}{|c|c|c|c|c|c|}
\hline \multirow{2}{*}{ Measure } & \multicolumn{2}{|c|}{ Typical readers $(\mathrm{N}=20)$} & \multicolumn{2}{|c|}{ Dyslexics (N = 20) } & \multirow{2}{*}{$\mathrm{T}$} \\
\hline & Mean & S.D. & Mean & S.D. & \\
\hline \multicolumn{6}{|l|}{ Visual Lexical Decision } \\
\hline Word Accuracy Percentage & 96.51 & 2.11 & 93.00 & 6.50 & -1.46 \\
\hline Word Reaction Time & 617.10 & 39.51 & 691.38 & 55.97 & $3.24^{* *}$ \\
\hline Pseudoword Accuracy Percentage & 98.35 & 1.45 & 87.80 & 12.57 & -2.34 \\
\hline Pseudoword Reaction Time & 685.10 & 58.97 & 814.25 & 127.26 & $2.67^{* *}$ \\
\hline \multicolumn{6}{|l|}{ Auditory Lexical Decision } \\
\hline Word Accuracy Percentage & 95.58 & 5.54 & 94.15 & 4.21 & -0.92 \\
\hline Word Reaction Time & 1042.03 & 114.25 & 1071.21 & 112.16 & 0.81 \\
\hline Pseudoword Accuracy Percentage & 91.01 & 5.59 & 88.36 & 8.54 & -1.15 \\
\hline Pseudoword Reaction Time & 1115.64 & 115.40 & 1149.67 & 124.73 & 0.89 \\
\hline \multicolumn{6}{|l|}{ Cross Modal Lexical Decision } \\
\hline Word Accuracy Percentage & 96.56 & 4.30 & 91.53 & 10.11 & $-1.99^{\circ}$ \\
\hline Word Reaction Time & 760.68 & 125.68 & 813.92 & 109.75 & 1.39 \\
\hline Pseudoword Accuracy Percentage & 96.72 & 4.41 & 91.53 & 9.70 & -2.12 \\
\hline Pseudoword Reaction Time & 823.61 & 120.06 & 861.51 & 219.42 & 0.66 \\
\hline
\end{tabular}

${ }^{*} p<0.05 ;{ }^{* *} p<0.01 ;{ }^{* * *} p<0.001$.

typical readers.

3.2.2. Auditory Lexical Decision

No significant differences were found between the two groups in accuracy and reaction time on the auditory task. 


\subsubsection{Cross Modal Lexical Decision}

When the stimuli were presented simultaneously in the visual and auditory modalities, the dyslexics were less accurate at recognizing words and pseudowords as compared to the typical readers. No differences in reaction time were found between the two groups.

\subsection{Differences between Presentation Modalities (Visual, Auditory, and Cross Modal) on the Lexical Decision Task}

In order to determine whether the presentation modality affected accuracy or reaction time during the lexical decision task, the data were processed using Repeated Measures MANOVA $(3 \times 2) 3$ levels of stimuli presentation (visual, auditory and cross modal) among both groups (dyslexics vs. typical readers).

Accuracy: A significant effect was found across groups for presentation channel (visual, auditory, and cross modal $)\left(\mathrm{F}_{(2,31)}=9.88, p<0.001\right)$. The greatest accuracy was for cross modal (simultaneous visual and auditory presentation) (94.2\%), followed by visual presentation (92.5\%), and the lowest accuracy was for auditory presentation (92\%). The differences stemmed from the gap in accuracy between the visual and auditory modalities and the integrative presentation in both modalities. In addition, an effect of group across presentation modalities was found $\left(\mathrm{F}_{(2,33)}=3.18, p=0.05\right)$, with lower accuracy for the dyslexic readers $(90.2 \%)$ than for the typical readers (95.5\%) in the three presentation fields. No significant interaction was found between groups for presentation field.

Reaction time: A significant effect was found across groups for presentation channel $\left(\mathrm{F}_{(2,31)}=84,87, p<\right.$ 0.001). The fastest reaction time was for visual presentation (745 msec on average), followed by cross modal (815 msec on average), and the slowest reaction time was for auditory presentation (1097 msec on average). The differences stemmed from the gap in reaction time between the three presentation methods (Figure 1 and Figure 2).

\section{Discussion}

The current study was aimed at comparing the speed and accuracy of the different modalities involved in word decoding between dyslexic readers and typical readers. Using behavioral measures, we examined the speed and timing of information processing in the visual, auditory, and cross modal channels. The basic research task was that of lexical decision (words and pseudowords), which is accepted as being indicative of orthographic-semantic processing (words) and phonological processing (pseudowords). It is also accepted as distinguishing between typical and dyslexic readers (Perfetti, 1994). The subjects in this study were "compensated" adult dyslexics and a control group of age-matched typical readers. In general, the results of this study validate previous findings as to the existence of slow reading and information processing at the linguistic level among dyslexics.

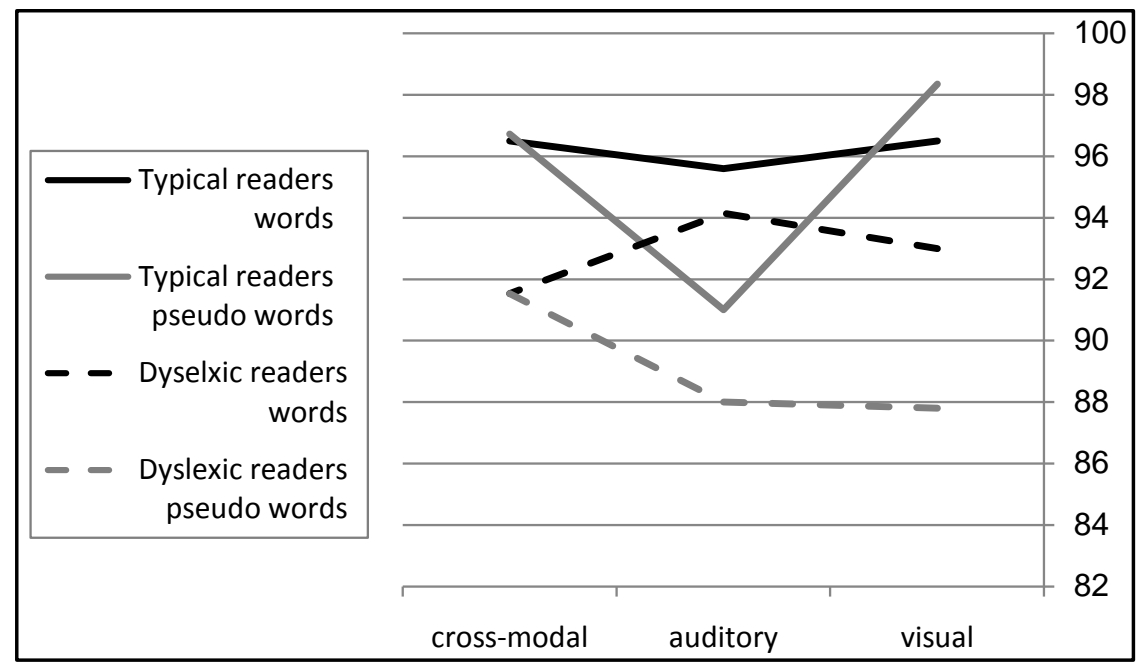

Figure 1. The differences in accuracy among typical and dyslexic readers in words and pseudo word processing in the three different modalities. 


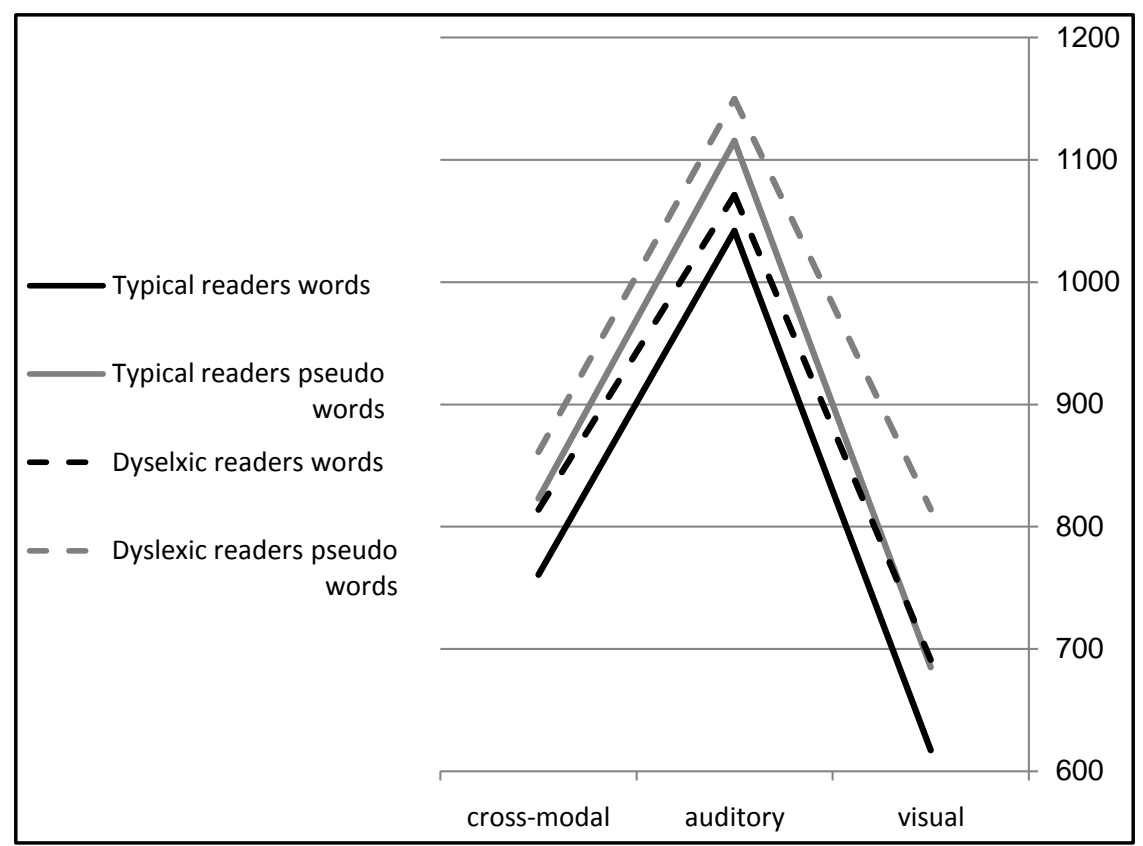

Figure 2. The differences in reaction time among typical and dyslexic readers in words and pseudo word processing in the three different modalities.

\subsection{SOP in the Visual Channel}

Most of the differences between the two groups in this study focused on the consistent slowness found among the dyslexic readers as compared to the typical readers in the SOP of the visual channel. In the visual lexical decision task, the dyslexics were slower at decoding words and pseudowords and were also less accurate at recognizing pseudowords as compared to the control group. These results provide support for the literature on adult dyslexics, which indicates that most of the difficulty in this population focuses on slow reading (Bruck, 1990) and phonological failure (Bell, McCaullum, \& Cox, 2003; Bruck, 1990; Ransby \& Swanson, 2003). Assuming that pseudoword reading is representative of phonological processing, it can be seen as an explanation for the dyslexic group’s inaccuracy when decoding pseudowords (see Breznitz \& Misra, 2003; Miller-Shaul \& Breznitz, 2004; Schiff \& Ravid, 2004).

The slowness observed among the dyslexics during visual processing of reading representations may be explained by the notion that these readers rely not only on the visual-orthographic channel, but also on the acoustic-phonological channel. In other words, for these readers, the visual pattern is also subject to sound correspondence. Based on the assumption that the stored orthographic pattern in the lexicon of these readers is impaired and therefore not readily accessible and automatically retrievable, as is probably the case among typical readers, dyslexics appear to process the written word pattern in two processing channels.

\subsection{SOP in the Auditory Channel}

No significant differences were found between the two groups on the auditory lexical decision task for accuracy or reaction time. These results are not surprising, given that the research tasks at this stage were based only on pseudowords. Thus, for both groups of readers, listening to the stimuli was akin to hearing speech structures. If we accept that the impairment characteristic of dyslexics relates to reading written language, then it would not be plausible to assume that they also have difficulty in relation to spoken language. It is true that reading involves some of the same processes and sources of information that are associated with speech; however, reading is also an independent activity. Processing speech is carried out in a biological perceptual system, while reading depends on a biological mechanism that initially served a different function in humans (such as spoken language) (Catts, 1986).

In the early 1990s, the definition of dyslexia was based on the gap between reading comprehension and listening comprehension. Aaron (1991) and Padget (1996) both described the dyslexia phenomenon as a difficulty 
with reading written words. There was an expected gap in reading comprehension and listening comprehension. Over the years, studies have presented evidence that dyslexics, especially adults, do not in fact have a listening comprehension problem (Bruck, 1990; Conners \& Olson, 1990; Katzir et al., 2004; Lefly \& Pennington, 1991; Ramus et al., 2003; Van Daal \& Van Der Leij, 1999). It is important to note, however, that these same studies reported on a listening comprehension weakness among dyslexics (Ransby \& Swanson, 1993). It was claimed that the dyslexics' phonological deficit was the cause of their listening comprehension difficulty rather than a listening comprehension deficit per se.

Moreover, the present study used stimuli containing simple words with medium frequency in the Hebrew language, and as such, there was no reason to assume that a Hebrew-speaking adult would have difficulty understanding these words, especially as they were presented to the subject via the auditory channel. It is accepted that dyslexics' comprehension is mainly impaired when reading complex and lengthy texts and not at the level of words or single sentences. It is therefore not surprising that the results of this study do not point to differences between groups on the auditory tasks.

\subsection{Cross Modality}

The rationale behind the presentation of stimuli to two sensory channels was based on the assumption that playing the stimuli to dyslexic readers as support for visual processing of the written symbol would ease their information processing, which would be expressed in accuracy and faster SOP. As a result, it was expected that the differences between the dyslexic readers and the typical readers would decrease. Indeed, a certain benefit to the dyslexics under the inter-sensory cross modal condition is suggested by the results showing that the reaction times of the dyslexics were similar to those of the typical readers on these tasks.

However, relative to the typical readers, the dyslexics made more word and pseudoword decoding errors under the cross modal condition. A comparison of accuracy under the visual, auditory, and cross modal conditions within the dyslexic group indicates a certain advantage of processing information in the cross modal condition rather than a single channel, as reflected by the higher percentage of correct answers. Nevertheless, a comparison of accuracy under the cross modal condition between groups shows that presentation to the two modalities simultaneously creates a disturbance of some kind that causes dyslexics to err more than typical readers. This finding may be explained by the assumption that despite having all of the information (visual and auditory) necessary for precise decoding, the dyslexics erred more due to impulsivity (speed/accuracy trade-off) and the burden on their system of receiving simultaneous stimuli in two processing channels.

These results are in line with recent brain research studies which have found that the dyslexic readers have difficulties in creating audiovisual constructs which can be used automatically and generate fluent reading (Blomert, 2011). In this study when information was given together and correctly in both modalities the dyslexic readers did not need to use these constructs and performed as well as the typical readers.

\subsection{Differences between the Three Presentation Modalities (Visual, Auditory, and Cross Modal)}

An examination of the differences between groups on the research tasks showed that the greatest accuracy in both groups was for the cross modal task and that no significant differences were found between the visual and auditory modalities. Thus, it is possible that simultaneous presentation of the information to both channels in both groups contributes to a more accurate performance of the task. An examination of reaction time on this task shows that the fastest performance was on the visual task, followed by the cross modal, and the slowest performance was on the auditory task.

These findings are consistent with the type of processing carried out in the various modalities, based on the characteristics of these sensory systems. It is known that the visual processing of words is holistic, meaning that each word is perceived as one pattern, and takes place faster than auditory processing, which is sequential (Breznitz, 2002a). The present findings are in line with this fact and show that visual recognition of a word is faster than its auditory recognition. In addition, the reading process begins in the visual channel, and as such, this channel has another advantage in terms of processing rate (Adams, 1990). Ben Artzi and Marks (1995) also demonstrated that when two stimuli are presented simultaneously, there is preference for the visual over the auditory modality. They found that subjects relate more to visual than to auditory information when two stimuli are presented simultaneously in the two modalities. The subjects erred less and responded more quickly when 
judging a sequence of stimuli according to the visual rather than the auditory stimulus.

\section{Conclusions and Future Research}

In conclusion, the results of this study support the claim that the basic failure in reading among compensated adult dyslexics, even after years of exposure to printed material, can generally be attributed to the visual channel and specifically to the speed of information processing within this channel. A disruption in the timing between the two processing channels begins in the perceptual stage and accumulates up to the completion of processing the linguistic stimulus. As the SOP timing is essential to the grapheme/phoneme conversion process used for precise decoding, this general slowness and its various stages contribute to the disruption of precise decoding.

Taking into consideration the limitations of the information processing system, which pertain to the decoding activity as well, the decoding process among dyslexics is lengthy and is not synchronized in terms of speed. Consequently, this process is not economical in cerebral processing terms and makes it difficult for this population to create precise patterns in the mental lexicon. The results of this study strengthen the claim that supporting these processing systems, which provide inter-sensory cross modal, may ease the difficulty and even failure experienced by dyslexic readers. Recent research has indicated that the human brain is flexible to change following training. As the present study suggests the importance of SOP and its synchronization to the quality of decoding, it is possible that a program could be developed to train the brain to process information more rapidly and thereby enable more efficient inter-channel synchronization and a more precise decoding process.

Based on the results of this study, future research should focus on the performance of various reading functions and not only on lexical decision tasks. It is also necessary to control the type of phonological and orthographic processing by using tasks that examine this processing directly.

\section{References}

Adams, M. J. (1990). Beginning to Read: Thinking and Learning about Print. Cambridge, MA: MIT Press.

Beery, C. (1967). Timing of Cognitive Responses in Naming Tasks. Nature, 215, 1203-1204. http://dx.doi.org/10.1038/2151203a0

Bell, S. M., McCallum, S. R., \& Cox, E. A. (2003). Towards a Research-Based Assessment of Dyslexia: Using Cognitive Measures to Identify Reading Disabilities. Journal of Learning Disabilities, 36, 505-516. http://dx.doi.org/10.1177/00222194030360060201

Ben, A., \& Marks, L. E. (1995). Visual-Auditory Interaction in Speeded Classification: Role of Stimulus Difference. Perception \& Psychophysics, 57, 1151-1162. http://dx.doi.org/10.3758/BF03208371

Ben-Dror, I., Pollatsek, A., \& Scarpati, S. (1991). Word Identification in Isolation and in Context by College Dyslexic Students. Brain and Language, 31, 308-327.

Birch, H. G., \& Belmont, L. (1964). Auditory-Visual cross Modal in Normal and Retarded Readers. American Journal of Orthopsychaitry, 34, 852-861. http://dx.doi.org/10.1111/j.1939-0025.1964.tb02240.x

Birch, H. G., \& Belmont, L. (1965). Auditory-Visual Integration Modal in Brain-Damaged and Normal Children. Developmental Medicine and Child Neurology, 7, 135-144. http://dx.doi.org/10.1111/j.1469-8749.1965.tb10904.x

Blank, M., \& Bridger, W. H. (1966). Deficiencies in Verbal Labeling in Retarded Readers. American Journal of Orthopsychiatry, 36, 840-847. http://dx.doi.org/10.1111/j.1939-0025.1966.tb02411.x

Bolmert, L. (2011). The Neural Signature of Orthographic-Phonological Binding in Successful and Failing Reading Development. NeuroImage, 57, 695-703. http://dx.doi.org/10.1016/j.neuroimage.2010.11.003

Bowers, P. G., \& Wolf, M. (1993). Theoretical Links among Naming Speed, Precise Timing Mechanisms and Orthographic Skill in Dyslexia. Reading and Writing, 5, 69-85. http://dx.doi.org/10.1007/BF01026919

Bowers, P., Golden, J., Kennedy, A., \& Young, A. (1994). Limits upon Orthographic Knowledge Due to Processing Indexed by Naming Speed. In V. W. Berninger (Ed.), The Varieties of Orthographic Knowledge I. Theoretical and Developmental issues (pp. 173-218). Dordrect: Kluwer Academic.

Breznitz, Z. (2001). The Determinants of Reading Fluency: A Comparison of Dyslexic and Average Readers. In M. Wolf (Ed.), Dyslexia, Fluency and the Brain (pp. 245-276). Cambridge, MA: York Press.

Breznitz, Z. (2002a). Asynchrony of Visual-Orthographic and Auditory-Phonological Word Recognition Processes: An Underlying Factor in Dyslexia. Reading and Writing, 15, 15-42. http://dx.doi.org/10.1023/A:1013864203452

Breznitz, Z. (2002b). Frequency and Characterization of Reading Difficulties and Disabilities among Fourth Grade Readers in the Jewish Sector of Israel. Report submitted to the Education. Jerusalem. 
Breznitz, Z. (2006). Fluency in Reading: Synchronization of Processes. Mahwah, NJ: Lawrence Erlbaum and Associates.

Breznitz, Z., \& Meyler, A. (2003). Speed of Lower-Level Auditory and Visual Processing as a Basic Factor in Dyslexia: Electrophysiological Evidence. Brain \& Language, 85, 166-184. http://dx.doi.org/10.1016/S0093-934X(02)00513-8

Breznitz, Z., \& Misra, M. (2003). Speed of Processing of the Visual-Orthographic and Auditory-Phonological Systems in Adult Dyslexics: The Contribution of “Asynchrony” to Word Recognition Deficits. Brain \& Language, 85, $486-502$. http://dx.doi.org/10.1016/S0093-934X(03)00071-3

Brickenkamp, R., \& Zillmer, E. A. (1995). Concentration Endurance Test (d2 Test of Attention). Odessa, FL: Psychological Assessment Resources, Inc.

Bruck, M. (1990). Word-Recognition Skils of Adults with Childhood Diagnoses of Dyslexia. Developmental Psychology, 26, 439-454. http://dx.doi.org/10.1037/0012-1649.26.3.439

Bruck, M. (1992). Persistence of Dyslexics’ Phonological Awareness Deficits. Developmental Psychology, 28, 874-886. http://dx.doi.org/10.1037/0012-1649.28.5.874

Bruck, M. (1998). Outcomes of Adults with Childhood Histories of Dyslexia. In C. Hulme, \& J. R. Malatesha (Eds.), Reading and Spelling: Development and Disorders (pp. 179-200). Mahwah, NJ: Lawrence Erlbaum.

Brunswick, N., McCrory, E., Price, C. J., Frith, C. D. \& Frith, U. (1999). Explicit and Implicit Processing of Words and Pseudowords by Adult Developmental Dyslexics. Brain, 122, 1901-1917. http://dx.doi.org/10.1093/brain/122.10.1901

Catts, H. W. (1986). Speech Production/Phonological Deficits in Reading-Disordered Children. Journal of Learning Disabilities, 19, 504-508. http://dx.doi.org/10.1177/002221948601900813

Compton, D. L., \& Carlislie, J. F. (1994) Speed of Word Recognition as a Distinguishing Characteristic of Reading Disabilities. Educational Psychology Review, 6, 115-140. http://dx.doi.org/10.1007/BF02208970

Corcos, E. \& Willows, D. M. (1993). The Processing of Orthographic Information. In D. N. Willows, R. S. Kruk, \& E. Corcos (Eds.), Visual Processing in Reading and Reading Disabilities (pp. 163-190). Hillsdale, NJ: Lawrence Erlbaum.

Davidson, R. J., Leslie, S. C., \& Saron, C. D. (1990). Reaction Time Measures of Interhemispheric Transfer Time in Reading Disabled and Normal Children._Neuropsychologia, 28, 471-485. http://dx.doi.org/10.1016/0028-3932(90)90073-W

Demb, J. B., Poldrack, R. A., \& Gabrieli, J. D. E. (1999). Functional Neuroimaging of Word Processing in Normal and Dyslexic Readers. In R. Klein, \& P. McMullen (Eds.), Converging Methods for Understanding Reading and Dyslexia. Cambridge, MA: MIT Press.

Elbro, C., Nielsen, I., \& Peterson, D. K. (1994). Dyslexia in Adults: Evidence for Deficits in Non-Word Reading and in the Phonological Representation of Lexical Items. Annals of Dyslexia, 44, 205-226. http://dx.doi.org/10.1007/BF02648162

Farmer, M. E., \& Klein, R. (1995). The Evidence for a Temporal Processing Deficit Linked to Dyslexia: A Review. Psychonomic Bulletin and Review, 2, 460-493. http://dx.doi.org/10.3758/BF03210983

Flowers, D. L. (1995). Neuropsychological Profiles of Persistent Reading Disability and Reading Improvement. In C. K. Leong, \& R. M. Joshi (Eds.), Developmental and Acquired Dyslexia (pp. 61-77). Dordrecht: Kluwer Academic Publishers. http://dx.doi.org/10.1007/978-94-017-1241-5 5

Friedes, D. (1974). Human Information Processing and Sensory Modality: Cross-Modal Functions, Information Complexity, Memory and Deficit. Psychological Bulletin, 81, 284-310. http://dx.doi.org/10.1037/h0036331

Galaburda, A. M. (1993). Dyslexia and Development: Neurobiological Aspects of Extra-Ordinary Brains. Cambridge, MA: Harvard University Press.

Galaburda, A. M., Sherman, G. F., Rosen, G. D., Aboitiz, F., \& Geschwind, N. (1985). Developmental Dyslexia: Four Consecutive Patients with Cortical Anomalies. Annals of Neurology, 18, 222-233. http://dx.doi.org/10.1002/ana.410180210

Galaburda, A., \& Livingstone, M. (1993). Evidence for a Magnocellular Defect in Developmental Dyslexia. In P. Tallal, A. M. Galaburda, R. R. Llinas, \& C. von Eurler (Eds.), Temporal Information Processing in the Nervous System. Annals of the New York Academy of Sciences (pp. 70-82).

Gottardo, A., Siegel, L. S., \& Stanovich, K. E. (1997). The Assessment of Adults with Reading Disabilities: What Can We Learn from Experimental Tasks? Journal of Research in Reading, 20, 42-54. http://dx.doi.org/10.1111/1467-9817.00019

Greene, B. A., \& Royer, J. M. (1994). A Developmental Review of Response Time Data That Support a Cognitive Components Model of Reading. Educational Psychology Review, 6, 141-172. http://dx.doi.org/10.1007/BF02208971

Hale, S. (1990). A Global Developmental Trend in Cognitive Processing Speed. Child Development, 61, 653-663. http://dx.doi.org/10.2307/1130951

Harrar, V., Tammam, J., Perez-Bellido, A., Pitt, A., Stein, J., \& Spence, C. (2014). Multisensory Integration and Attention in Developmental Dyslexia. Current Biology, 24, 531-535. http://dx.doi.org/10.1016/j.cub.2014.01.029

Hayes, E. A., Warrier, C. M., Nicol, T. G., Zecker, S. G., \& Kraus, N. (2003). Neural Plasticity Following Auditory Training in Children with Learning Problems. Clinical Neurophysiology, 114, 673-684. 
http://dx.doi.org/10.1016/S1388-2457(02)00414-5

Humphreys, P., Kaufmann, W. E., \& Galaburda, A. M. (1990). Developmental Dyslexia in Women: Neuropathological Findings in Three Patients. Annals of Neurology, 28, 727-738. http://dx.doi.org/10.1002/ana.410280602

Hynd, G. W., \& Semrud-Clikeman, M. (1989). Dyslexia and Brain Morphology. Psychological Bulletin, 106, 447-482. http://dx.doi.org/10.1037/0033-2909.106.3.447

Kail, R. (1991). Developmental Changes in Speed of Processing during Childhood and Adulescene. Psychological Bulletin, 109, 490-501. http://dx.doi.org/10.1037/0033-2909.109.3.490

Kail, R., \& Hall, L. K. (1994). Processing Speed, Naming Speed, and Reading. Developmental Psychology, 30, 949-954. http://dx.doi.org/10.1037/0012-1649.30.6.949

Katzir, T., Shaul, S., Breznitz, Z., \& Wolf, M. (2004). The Universal and Unique in Dyslexia: A Cross-Linguistic Investigation of Reading and Reading Fluency in Hebrew and English Speaking Children with Reading Disorders. Reading and Writing, 17, 739-768. http://dx.doi.org/10.1007/s11145-004-2655-z

Kolers, P. A., \& Brewster, J. M. (1985). Rhythms and Responses. Journal of Experimental Psychology: Human Perception and Performance, 11, 150-167. http://dx.doi.org/10.1037/0096-1523.11.2.150

Lefly, D. L., \& Pennington, B. F. (1991). Spelling Errors and Reading Fluency in Compensated Adult Dyslexics. Annals of Dyslexia, 41, 143-162. http://dx.doi.org/10.1007/BF02648083

Leinonen, S., Leppänen, P., Aro, M., Ahonen, T., \& Lyytinen, H. (2001). Heterogeneity in Adult Dyslexic Readers: Relating Processing Skills to the Speed and Accuracy of Oral Text Reading. Reading and Writing, 14, 265-296. http://dx.doi.org/10.1023/A:1011117620895

Leonard, C. M., Voeller, K. K., Lombardino, L. J., Morris, M. K., Hynd, G. W., Alexander, A. W. et al. (1993). Anomalous Cerebral Structure in Dyslexia Revealed with Magnetic Resonance Imaging. Archives of Neurology, 50, 461-469. http://dx.doi.org/10.1001/archneur.1993.00540050013008

Leong, C. K. (1999). Phonological and Morphological Processing in Adult Students with Learning/Reading Disabilities. Journal of Learning Disabilities, 32, 224-238. http://dx.doi.org/10.1177/002221949903200304

Livingstone, M. S., Rosen, G. D., Drislane, F. W., \& Galaburda, A. M. (1991). Physiological and Anotomical Evidence for a Magnocellular Deficit in Developmental Dyslexia. Proceedings of the National Academy of Sciences of the United States of America, 88, 7943-7947. http://dx.doi.org/10.1073/pnas.88.18.7943

Lovegrove, W., \& Slaghuis, W. (1989). How Reliably Are Visual Differences Found in Dyslexia? Irish Journal of Psychology, 10, 542-550. http://dx.doi.org/10.1080/03033910.1989.10557769

Lovegrove, W., Slaghuis, W., Bowling, A., Nelson, P., \& Geeves, T. (1986). Spatial Frequency Processing and the Prediction of Reading Ability: A Preliminary Investigation. Perception and Psychophysics, 40, 440-444. http://dx.doi.org/10.3758/BF03208204

Merzenich, M. M., Schreiner, C. E., Jenkins, W., \& Wang, A. (1993) Neural Mechanisms Underlying Temporal Cross Modal, Segmentation, and Input Sequence Representation: Some Implications for the Origin of Learning Disabilities. In P. Tallal, \& A. M. Galaburda (Eds.), Temporal Information Processing in the Nervous System: Special Reference to Dyslexia and Dysphasia. Annals of the New York Academy of Sciences (pp. 1-22). New York: New York Academy of Sciences

Muehl, S., \& Kremenak, S. (1966). Ability to Match Information within and between Auditory and Visual Sense Modalities and Subsequent Reading Achievement. Journal of Educational Psychology, 57, 230-239. http://dx.doi.org/10.1037/h0023557

National Center for Evaluation (2000). Comprehension Test, Israeli Psychometric Scholastic Aptitude Test. Tel Aviv.

Neisser, U. (1967). Cognitive Psychology. East Norwalk, CT: Appleton Century-Crofts.

Padget, S. Y., Knight, D. F., \& Sawyer, D. A. (1996). Tennessee Meets the Challenge of Dyslexia. Annals of Dyslexia, 46, 51-72. http://dx.doi.org/10.1007/BF02648171

Pennington, B. F., McCabe. L. L., Smith, S. D., Lefly, D. L., Bookman, M. D., Kimberling, W. J., \& Lubas, H. A. (1986). Spelling Errors in Adults with a Form of Familial Dyslexia. Child Development, 126, 841-865.

Perfetti, C. A. (1994). Psycholinguistics and Reading Ability. In M. A. Gernsbacher (Ed.), Handbook of Psycholinguistics (pp. 849-885). San Diego: Academic Press.

Plaut, D. C., McClelland, J. L., Seidenberg, M. S., \& Patterson, K. (1996). Understanding Normal and Impaired Word Reading: Computational Principles in Quasi-Typical Domains. Psychological Review, 103, 56-115.

http://dx.doi.org/10.1037/0033-295X.103.1.56

Poldrack, R. A. (2001). A Structural Basis for Developmental Dyslexia:Evidence from Diffusion Tensor Imaging. In M. Wolf (Ed.), Dyslexia, Fluency and the Brain (pp. 213-234).

Ramus, F., Rosen, S., Dakin, S. C., Day, B. L., Casellote, S., White, S., \& Frith, U. (2003). Theories of Developmental Dyslexia: Insights from a Multiple Case Study of Dyslexic Aduits. Brain, 126, 841-865. 
http://dx.doi.org/10.1093/brain/awg076

Ransby, M. J., \& Swanson, L. H. (2003). Reading Comprehension Skills of Young Adults with Childhood Diagnoses of Dyslexia. Journal of Learning Disabilities, 36, 538-555. http://dx.doi.org/10.1177/00222194030360060501

Raven, J. C. (1965). Advanced Progressive Matrices Sets I and II. London: H. K. Lewis.

Rayner, K., Foorman, B. R., Perfetti, C. A., Pesetsky, D., \& Seidenberg, M. S. (2001). How Psychological Science Informs the Teaching of Reading. Psychological Science in the Public Interest, 2, 31-74. http://dx.doi.org/10.1111/1529-1006.00004

Reitsma, P. (1989). Orthographic Memory and Learning to Read. In P. G. Aaron, \& R. M. Joshi (Eds.), Reading and Writing Disorders in Different Orthographic Systems. The Netherlands: Kluwer Academic. http://dx.doi.org/10.1007/978-94-009-1041-6_3

Robinson, G. M. (1977). Rhythmic Organization in Speech Processing. Journal of Experimental Psychology: Human Perception and Performance, 3, 83-91. http://dx.doi.org/10.1037/0096-1523.3.1.83

Rose, S. A., Feldman, J. F., Janowski, J. J., \& Futterweit, L. R. (1999). Visual and Auditory Temporal Processing, CrossModal Transfer, and Reading. Journal of Learning Disabilities, 32, 256-266. http://dx.doi.org/10.1177/002221949903200307

Rumsey, J. M., Zametkin, A. J., Andreaason, P., Hanaahan, A. P., Hamburger, S. D., Aquino, T., King, A. C., Pikus, A., \& Cohen, R. M. (1994). Normal Activation of Frontotemporal Language Cortex in Dyslexia as Measured with Oxygen 15 Positron Emission Tomography. Archives of Neurology, 51, 27-38. http://dx.doi.org/10.1001/archneur.1994.00540130037011

Schiff, R., \& Ravid, D. (2004). Representing Written Vowels in University Students with Dyslexia Compared with Normal Hebrew Readers. Annals of Dyslexia, 54, 39-64. http://dx.doi.org/10.1007/s11881-004-0003-2

Seidenberg, M. S. (1990). Dyslexia in a Computational Model of Word Recognition in Reading. In P. B. Gough, L. C. Ehri, \& R. Trieman (Eds.), Reading Acquisition (pp. 243-273). Hillsdale, NJ: Erlbaum.

Seidenberg, M. S., \& McClleland, J. L. (1989). A Distributed Developmental Model of Word Recognition and Naming. Psychological Review, 96, 523-568. http://dx.doi.org/10.1037/0033-295X.96.4.523

Share, D. L. (1994). Deficient Phonological Processing in Disabled Readers Implicates Processing Deficits beyond the Phonological Module. In K. P. van den Bos, L. S. Siegal, D. J. Bakker, \& D. L. Share (Eds.), Current Directions in Dyslexia Research. Lisse: Swets \& Zeitlinger B. V.

Shatil, E. (1997). One Minute Test for Words and Pseudowords. Unpublished Test, Haifa: University of Haifa.

Shaywitz, S. E. (1996). Dyslexia. Scientific American, 275, 98-140. http://dx.doi.org/10.1038/scientificamerican1196-98

Shaywitz, S. E., Fletcher, J. M., Holahan, J. M., Shneider, A. E., Marchione, K. E., Stueberg, K. K., Francis, D. J., Pugh, K. R., \& Shaywitz, B. A. (1999). Persistence of Dyslexia: The Connecticut Longitudinal Study at Adolescence. Pediatrics, 104, 1351-1359. http://dx.doi.org/10.1542/peds.104.6.1351

Snowling, M. J., \& Nation, K. A. (1997). Language, Phonology, and Learning to Read. In C. Hulme, \& M. Snowling (Eds.), Dyslexia: Biology, Cognition and Intervention (pp. 153-166). London: Whurr.

Snowling, M., Nation, K., Moxham, P., Gallagher, A., \& Frith, U. (1997). Phonological Processing Skills of Dyslexic Students in Higher Education: A Preliminary Report. Journal of Research in Reading, 20, 31-41. http://dx.doi.org/10.1111/1467-9817.00018

Stein, J. F., \& McAnally, K. I. (1995). Auditory Temporal Processing in Developmental Dyslexics. Irish Journal of Psychology, 16, 220-228. http://dx.doi.org/10.1080/03033910.1995.10558058

Stein, J., \& Walsh, V (1997). To See But Not to Read; the Magnocellular Theory of Dyslexia. Trends in Neurosciences, 20, 147-152. http://dx.doi.org/10.1016/S0166-2236(96)01005-3

Sterritt, G. M., \& Rudnick, M. (1966). Auditory and Visual Rhythm Perception in Relation to Reading Ability in Fourth Grade Boys. Perceptual and Motor Skills, 22, 859-864. http://dx.doi.org/10.2466/pms.1966.22.3.859

Stigler, J. W., Nusbaum, H. C., \& Chalip, L. (1988). Developmental Changes in Speed of Processing: Central Limiting Mechanism of Skill Transfer? Child Development, 59, 1144-1153. http://dx.doi.org/10.2307/1130281

Treiman, R. (2000). The Foundations of Literacy. Current Directions in Psychological Science, 9, 89-92. http://dx.doi.org/10.1111/1467-8721.00067

Van Daal, V., \& van der Leij, A. (1999). Developmental Dyslexia: Related to Specific or General Deficits. Annals of Dyslexia, 49, 71-104. http://dx.doi.org/10.1007/s11881-999-0020-2

Vellutino, F. R., Fletcher, J. M., Snowling, M. J., \& Scanlon, D. M. (2004). Specific Reading Disability (Dyslexia): What Have We Learned in the Past Four Decades? Journal of Child Psychology and Psychiatry, 45, 2-40.

http://dx.doi.org/10.1046/j.0021-9630.2003.00305.x

Wagner, R. K., \& Barker, T. A. (1994).The Development of Orthographic Processing Ability. Neuropsychology and Cogni- 
tion, 8, 243-276. http://dx.doi.org/10.1007/978-94-017-3492-9_8

Willows, D. M., Kruk, R., \& Corcos, E. (1993). Are There Differences between Disabled and Normal Readers in Their Processing of Visual Information? In D. M. Willows, R. S. Kruk, \& E. Corcos (Eds.), Visual Processes in Reading and Reading Disabilities (pp. 265-285). Hillsdale, NJ: Lawrence Erlbaum.

Wolf, M., Vellutino, F., \& Gleason, J. B. (1998). A Psycholinguistic Account of Reading. In J. B. Gleason, \& N. Bernstein Ratner, Psycholinguistics (2nd ed.). New York: Harcourt Brace.

Yap, R., \& van der Leij, A. (1993). Word Processng in Dyslexics. Reading and Writing, 5, 261-279. http://dx.doi.org/10.1007/BF01027391

Zecker, S. G. (1991). The Orthographic Code: Developmental Trends in Reading-Disabled and Normally-Achieving Children. Annals of Dyslexia, 41, 178-192. http://dx.doi.org/10.1007/BF02648085 
Scientific Research Publishing (SCIRP) is one of the largest Open Access journal publishers. It is currently publishing more than 200 open access, online, peer-reviewed journals covering a wide range of academic disciplines. SCIRP serves the worldwide academic communities and contributes to the progress and application of science with its publication.

Other selected journals from SCIRP are listed as below. Submit your manuscript to us via either submit@scirp.org or Online Submission Portal.
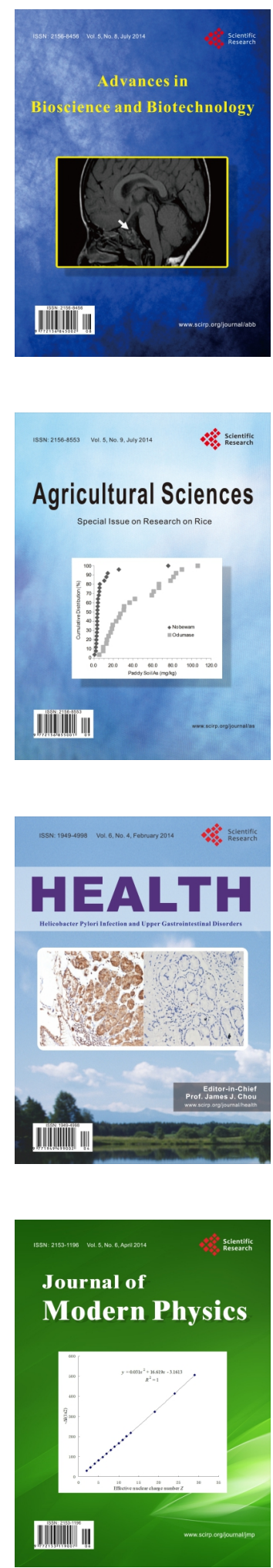
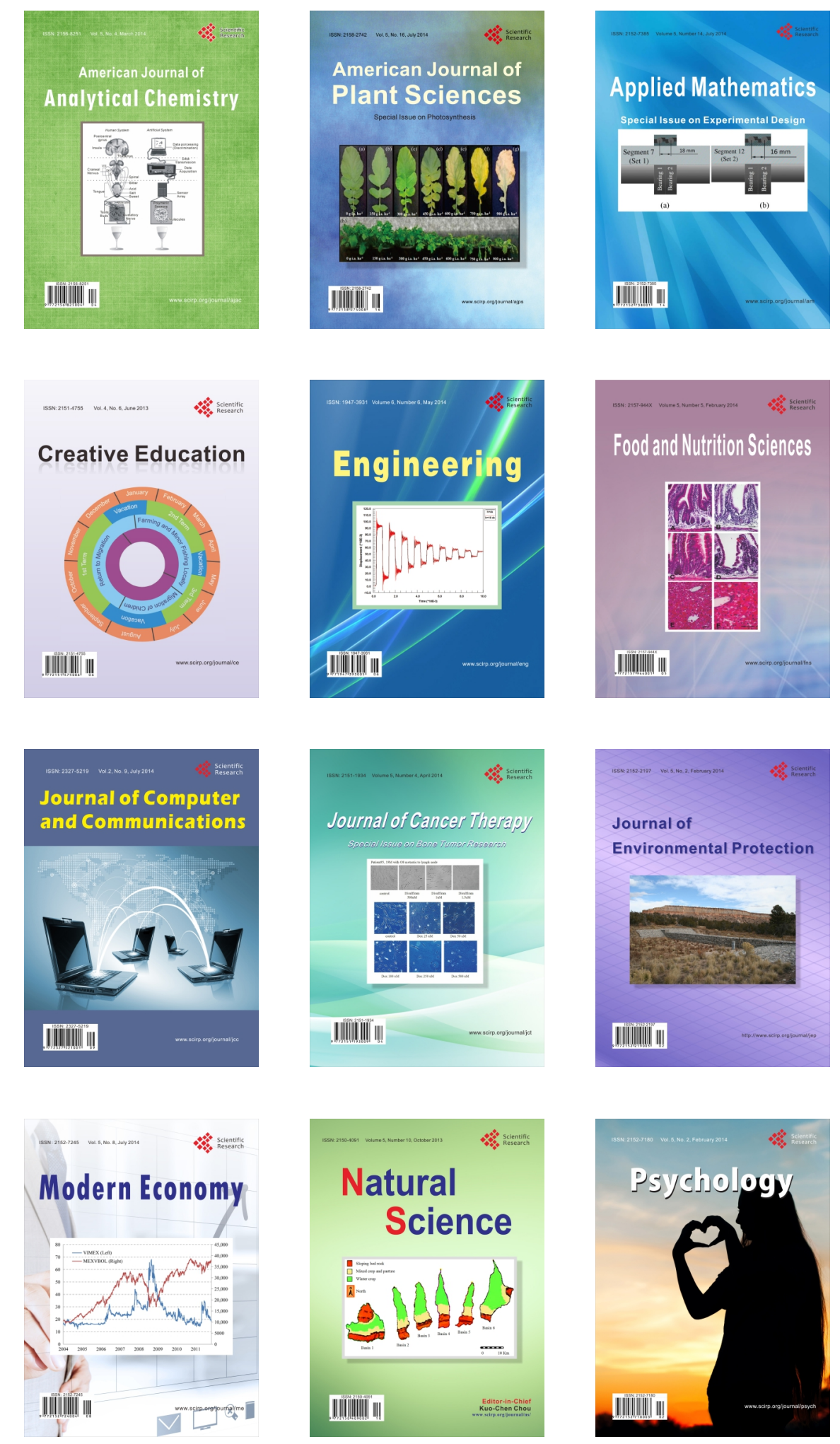